\title{
ANÁLISE DE DOCUMENTOS ESCOLARES DA EDUCAÇÃO PROFISSIONAL SOB OS ASPECTOS DA POLÍTICA NACIONAL DE EDUCAÇÃO AMBIENTAL: O CONTEXTO DO INSTITUTO FEDERAL DO PARANÁ (IFPR) CAMPUS CURITIBA
}

\author{
Augusto Lima da Silveira ${ }^{1}$ \\ Rodrigo Berté ${ }^{2}$ \\ Marcos Rogério Maioli ${ }^{3}$
}

Resumo: A Educação Ambiental deve favorecer a sensibilização sobre o meio ambiente, diante disso o objetivo geral do estudo foi identificar, nas principais normativas do IFPR, se a formação do aluno contempla, além dos aspectos profissionais, diretrizes ambientais previstas na Política Nacional de Educação Ambiental (PNEA). Foram analisados 10 documentos da instituição de 2008 a 2014, com base em buscas pelas palavras-chave "meio ambiente", "ambiental" e "sustentabilidade". O contexto em que estavam inseridas foi analisado de acordo com a PNEA e a literatura da área. Os termos de busca foram encontrados em 6 dos 10 documentos analisados, refletindo uma considerável difusão destes conceitos, indicando articulação da instituição com a PNEA.

Palavras-chave: Educação Ambiental; Educação Profissional; Meio Ambiente; Sustentabilidade. 


\section{Introdução}

A Constituição Federal de 1988 determina que a educação é um direito de todo cidadão e que os entes federados devem propiciar as condições necessárias para que ela ocorra de forma efetiva (BRASIL, 1988). Para estabelecer as diretrizes necessárias ao fornecimento de um ensino de qualidade, indicada pela Constituição, foi estabelecida a Lei de Diretrizes e Bases da Educação, a LDB que afirma em um de seus princípios (Art. $3^{\circ}$ ) a garantia de um ensino com padrão de qualidade.

Neste sentido a estruturação do processo de ensino, propiciada por esta lei, trouxe não só os procedimentos para a oferta educacional do país, o papel do Estado e dos municípios, mas também as necessidades para a formação dos cidadãos brasileiros (BRASIL, 1996).

Um dos aspectos previstos na Constituição Federal, e que atualmente tem merecido grande destaque, é a necessidade de formar cidadãos conscientes das questões ambientais, bem como da relação indissociável entre sociedade e meio ambiente (BRASIL, 1988). De acordo com Layrargues (2004) a Educação Ambiental propõe práticas pedagógicas pautadas nas questões ambientais, as quais devem atuar na conscientização e na formação de alunos com senso crítico capazes de questionar a realidade.

Desta forma, para efetivar a Educação Ambiental como prática de ensino e favorecer a conscientização sobre o meio ambiente foi regulamentada a Lei 9.795 de abril de 1999 que instituiu a Política Nacional de educação Ambiental estabelecendo os seus princípios e formas de execução. $O$ tema, segundo esta lei, não deve ser tratado em uma disciplina isolada no currículo, mas sim como um tema transversal a ser trabalhado em todas as disciplinas de forma integrada e conjunta (BRASIL, 1999).

A sistematização da Educação Ambiental como um dos componentes curriculares do ensino no país foi estabelecida, de fato em nível nacional, por meio das Diretrizes Curriculares Nacionais para a Educação Ambiental, resolução $n^{\circ}$. 2 de 15 de junho de 2012 do Ministério da Educação. A resolução estabelece de que maneira a Educação Ambiental deve estar inserida nos processos educacionais do país e aborda aspectos sobre os princípios, objetivos e a organização curricular para que a temática seja adequadamente tratada. Especificamente sobre a formação profissional estabelece em seu Art. 9:

Art. 9o Nos cursos de formação inicial e de especialização técnica e profissional, em todos os níveis e modalidades, deve ser incorporado conteúdo que trate da ética socioambiental das atividades profissionais (BRASIL, 2012 grifo nosso). 
Segundo as Diretrizes Curriculares Nacionais, as questões ambientais devem ser tratadas por meio da interdisciplinaridade ou da inserção dos conceitos em componentes já constantes no currículo, conforme prevê o Art. 16. De acordo com a natureza dos cursos, em especial na educação profissional técnica de nível médio, outras formas de abordar a Educação Ambiental também podem ser previstas levando em consideração a organização curricular.

Os esforços para a formação de pessoas mais conscientes são justificados devido à atual situação ambiental. Vivenciamos um quadro de elevado processo de degradação e inviabilização dos recursos naturais, fruto do desenvolvimento das atividades humanas que poluem e esgotam os ecossistemas para produção de tecnologias e insumos frente a uma população mundial que está a cada dia maior (KLUCZKOVSKI, 2015).

A maior parte da população vive nos centros urbanos e esta característica intensifica a degradação destes locais, além de tornar os desafios de manter um ambiente saudável e equilibrado bastante complexos. Desta maneira, reverter a atual situação depende de uma mudança drástica nos conhecimentos, valores e comportamentos relacionados ao aspecto econômico do desenvolvimento no ambiente urbano (COSTA, 2008).

Neste sentido, no âmbito educacional, é necessário criar situações para a reflexão a respeito das questões ambientais estabelecidas na atualidade, em ecossistemas a cada dia mais degradados, por meio de um conjunto de ações multidisciplinares que levem o aluno a atribuir sentido para 0 estudo do meio ambiente e de sua vinculação com as práticas diárias (JACOBI, 2003).

Para que a prática da Educação Ambiental seja efetivada, um fator de grande importância a ser considerado é a concepção que se tem da relação entre sociedade e natureza. É inegável a grande necessidade de compreender o ambiente e as relações de produção da atual sociedade para que a partir disso, novas ideias possam ser desenvolvidas para proporcionar uma existência mais equilibrada entre homem e recursos naturais (SILVA, 2010). De acordo com Loureiro (2012) a educação ambiental deve explicitar a ligação indissociável entre sociedade e natureza, sendo a premissa básica para a formação de uma consciência capaz de discutir e propor novas formas de produção com baixos níveis de impacto.

Neste sentido, Barbieri (2011) sugere que uma maior compreensão de conceitos relativos a meio ambiente pode auxiliar para que sejam propostas melhorias e formas de superar o senso comum nesta área da educação, uma vez que quando as concepções de natureza são equivocadas, todas as ações para a Educação Ambiental são ineficazes na busca pelo equilíbrio e desenvolvimento sustentável.

Para a adequada aplicação dos dispositivos legais, os documentos que regem as atividades das instituições de ensino devem contemplar as diretrizes relacionadas aos aspectos ambientais. Diante do exposto o objetivo geral do Revbea, São Paulo, V. 12, № 5: 10-25, 2017. 
estudo foi identificar, através das principais normativas do Instituto Federal do Paraná, se as políticas para a formação do aluno contemplam, além dos critérios da formação profissional, também os aspectos ambientais, a integração entre o homem e a natureza estabelecidos pela Política Nacional de Educação Ambiental e as Diretrizes Curriculares Nacionais para a Educação Ambiental.

\section{Metodologia}

O Instituto Federal do Paraná (IFPR) foi criado em 2008 pela Lei 11.892 que instituiu a educação profissional e tecnológica no âmbito federal. Atualmente a instituição é especializada na oferta gratuita de educação profissional tecnológica de nível médio e superior contando com 21 campi em todo o estado e permanece em expansão (IFPR a, 2015). O universo delimitado para este estudo compreende o campus Curitiba que oferta 24 cursos técnicos na modalidade presencial, dos quais 16 são subsequentes.

A escolha da educação profissional ocorreu devido à necessidade de verificar de que forma a educação de alunos, que buscam uma formação voltada ao mundo do trabalho, é pensada no âmbito das diretivas da Política Nacional de Educação Ambiental - PNEA (BRASIL, 1999).

O estudo foi desenvolvido com base na busca por palavras-chave relacionadas à temática da Educação Ambiental. Trata-se da realização de uma análise documental exploratória. Foram utilizados os termos "meio ambiente", "ambiental" e "sustentabilidade" para localizar junto aos documentos, os trechos que tratavam dessas questões. Os conceitos envolvidos foram então comparados à Política Nacional de Educação Ambiental (PNEA) e à literatura disponível para avaliar o grau de aderência no que trata a legislação, bem como as tendências pedagógicas sobre as questões ambientais utilizadas na instituição. A escolha dos termos de busca é resultado da verificação em literaturas relacionadas a área ambiental que indicou elevada incidência destas palavras.

Os documentos utilizados nas análises foram identificados por meio de siglas para facilitar as discussões e estão relacionados na Tabela 1 (próxima página).

Foram também utilizados na análise, os documentos relacionados aos cursos técnicos subsequentes da instituição (ofertados pelo campus Curitiba) como os planos de curso e os projetos pedagógicos, quando disponíveis no site da instituição. Os cursos utilizados na análise foram: Administração, Edificações, Eletromecânica, Eletrotécnica, Enfermagem, Eventos, Massoterapia, Mecânica, Processos Fotográficos, Produção de Áudio e Vídeo, Prótese Dentária, Radiologia, Saúde Bucal, Secretariado, Telecomunicações e Transações Imobiliárias. 
Tabela 1: Relação de documentos utilizados no estudo e as respectivas siglas.

DOCUMENTO

\begin{tabular}{ll}
\hline Regulamento: concepção de avaliação da aprendizagem & $\mathrm{RL}$ \\
\hline Regimento geral do IFPR & $\mathrm{RG}$ \\
\hline $\begin{array}{l}\text { Regimento interno do campus (Resolução no. 08 de 30 de } \\
\text { abril de 2014) }\end{array}$ & $\mathrm{RI}$ \\
\hline Plano de Desenvolvimento Institucional 2009 a 2013 & $\mathrm{PD}$ \\
\hline Plano de Desenvolvimento Institucional 2014 a 2018 & $\mathrm{PD}$ \\
\hline Manual dos Professores - IFPR campus Curitiba & $\mathrm{MP}$ \\
\hline $\begin{array}{l}\text { Desenvolvimento dos Servidores técnico-administrativos e } \\
\text { docentes (Resolução no. 44 de 09 de Dezembro de 2013) }\end{array}$ & $\mathrm{DS}$ \\
\hline $\begin{array}{l}\text { Estatuto do Instituto Federal do Paraná (Resolução } \\
\text { no02/2014 e Resolução no 02/2015) }\end{array}$ & $\mathrm{ES}$ \\
\hline
\end{tabular}

Fonte: os autores

O Regulamento $(R L)$ trata basicamente das diretrizes ao processo de avaliação ao qual os alunos do IFPR devem ser submetidos ao longo do processo de ensino. O IFPR utiliza a avaliação por conceitos e por este motivo o documento também traz os critérios para a conversão das notas e a divulgação do resultado final de desempenho.

No Regimento Geral (RG) são divulgadas as diretrizes gerais para a organização das atividades comuns a todo IFPR desde as questões administrativas até o processo de elaboração didático-científico, já o Regimento Interno (RI) organiza as questões referentes aos campi.

Os Planos de Desenvolvimento Institucional (PD e PD2) estabelecem as metas da instituição referentes ao seu processo de expansão e melhoria contínua nas áreas de ensino, pesquisa e extensão.

No Manual dos Professores (MP) são estabelecidas as atribuições do corpo docente da instituição de ensino.

A capacitação de professores e funcionários administrativos é regulamentada por meio da Resolução №. 44 de 09 de dezembro de 2013 (DS) que estabelece os aspectos relacionados à necessária formação continuada.

Por fim, o Estatuto do Instituto Federal do Paraná (ES) documenta o processo de gestão e que trata da organização de órgãos colegiados, da reitoria e do regime acadêmico para docentes e discentes. 


\title{
Resultados e discussões
}

\section{Definições do estudo}

Para favorecer o processo de análise dos resultados é preciso destacar as principais definições relacionadas aos termos de busca utilizados: meio ambiente, ambiental e sustentabilidade.

A Política Nacional do Meio Ambiente (Lei 6.938 de 31 de agosto de 1981) estabelece as diretrizes para a qualidade ambiental no país, bem como os mecanismos para promover a conservação ambiental. Uma das definições apresentadas na lei refere-se ao termo "meio ambiente":

\begin{abstract}
Art. 3o - Para os fins previstos nesta Lei, entende-se por:
I - meio ambiente, o conjunto de condições, leis, influências e interações de ordem física, química e biológica, que permite, abriga e rege a vida em todas as suas formas (BRASIL, 1981).
\end{abstract}

Para Barbieri (2007), considera-se meio ambiente não só os seres vivos e as suas interações no ambiente natural, mas também os locais construídos e modificados pela ação humana, como os grandes centros urbanizados, as estruturas viárias e de saneamento, por exemplo. Por este motivo o meio ambiente pode ser considerado não só um espaço de existência para os seres vivos, mas também a condição para a existência da vida no planeta.

Conforme a definição do dicionário, ambiental é um adjetivo para expressar algo relativo ao ambiente ou ao meio em que vivemos. A escolha desta palavra foi realizada para que as variações do termo "meio ambiente" fossem também consideradas nas análises realizadas nos documentos.

Já a "sustentabilidade" pode ser compreendida como a capacidade dos mais variados sistemas do planeta, incluindo a economia e os aspectos culturais, de se adaptarem em condições de contínua mudança observadas no planeta. O termo foi utilizado pela primeira vez em 1987 no relatório "Our Common Future" elaborado pela norueguesa Gro Harlem Brundtland para a Organização das Nações Unidas e apresenta uma visão voltada ao uso adequado dos recursos naturais, de forma a mantê-los em qualidade para futuras gerações aliando conservação e desenvolvimento (MILLER JR., 2011).

Os três termos de busca apresentam relação direta com as questões ambientais, sendo bastante frequentes em documentos e legislações. Desta forma a busca por estas palavras-chave forneceu informações importantes sobre como os conteúdos relativos a meio ambiente são tratados em âmbito institucional e nas políticas educacionais do ensino técnico. 


\section{Documentos institucionais}

A partir da análise dos documentos foi possível verificar que a questão ambiental se apresenta difundida em 4 dos 8 documentos analisados conforme a Tabela 2.

Tabela 2: Resultado das análises por palavras-chave em relação aos documentos institucionais.

\begin{tabular}{cccc}
\hline \multirow{2}{*}{ DOCUMENTOS } & \multicolumn{3}{c}{ INCIDENNCIAS DE PALAVRAS-CHAVE } \\
\cline { 2 - 4 } & MEIO AMBIENTE & AMBIENTAL & SUSTENTABILIDADE \\
\hline $\mathrm{RL}$ & 0 & 0 & 0 \\
\hline $\mathrm{RG}$ & 1 & 3 & 0 \\
\hline $\mathrm{RI}$ & 0 & 0 & 0 \\
\hline $\mathrm{PD}$ & 9 & 2 & 2 \\
\hline $\mathrm{PD} 2$ & 7 & 10 & 24 \\
\hline $\mathrm{MP}$ & 0 & 0 & 0 \\
\hline $\mathrm{DS}$ & 0 & 0 & 0 \\
\hline $\mathrm{ES}$ & 2 & 0 & 0
\end{tabular}

Fonte: os autores.

A baixa incidência dos termos de estudo pode indicar uma pequena preocupação com os aspectos ambientais no desenvolvimento das práticas de ensino.

Foi possível constatar que os termos pesquisados ficaram quase totalmente concentrados em 2 dos documentos de estudo, os Planos de Desenvolvimento Institucional PD2 e PD, com 41 e 13 incidências respectivamente.

Analisando os documentos que continham as palavras-chave, se observou que o Regimento Geral do IFPR (RG) menciona no seu Art. $4^{\circ}$ a questão ambiental especificamente ao demonstrar as finalidades da instituição:

O Instituto Federal do Paraná deverá promover a integração e a verticalização da educação básica à educação profissional e educação superior, com ênfase no desenvolvimento socioeconômico, nas potencialidades regionais, preservação do meio ambiente, transparência e gestão democrática (IFPR c, 2015, p. 4, grifo nosso). 
"ambiental" relacionado ao desenvolvimento de atividades de ensino, pesquisa e extensão no Regimento Geral (RG).

Um aspecto interessante verificado foi o aumento na incidência de termos pesquisados do PD em relação ao PD2. Tal constatação pode ser o reflexo de uma maior preocupação com questões relacionadas ao meio ambiente ao longo do desenvolvimento da instituição. $O$ aumento na preocupação por questões ambientais é um fator relativamente recente entre as organizações e é decorrente de uma maior pressão exercida pela sociedade, pelos impactos ambientais, pela escassez de recursos, enfim, de uma consciência da finitude dos recursos naturais (STADLER; MAIOLI, 2011; MAZZAROTTO; BERTE, 2013)

Os Planos de Desenvolvimento do IFPR preveem um desenvolvimento que considera a complexidade dos fatores ambientais, sociais e econômicos de forma que princípios de justiça social, preservação ambiental, equidade, cidadania e ética sejam difundidos ao longo das atividades de ensino, pesquisa e extensão (IFPR e, 2015; IFPR f, 2015). Esses documentos são os mais representativos em relação aos termos pesquisados, o que indica uma maior integração com as questões sociais e ambientais. Durante a análise dos contextos em que os termos estavam inseridos nos documentos constatou-se que em 4 das 9 ocorrências no PD o termo "meio ambiente" estava associado a questões sociais. Essa constatação reflete um dos objetivos propostos para a Educação Ambiental no Art. $5^{\circ}$ da PNEA (BRASIL, 1999).

De acordo com Reis e Bellini (2011) a Educação Ambiental deve considerar em sua ação, as características do meio social em que os alunos estão envolvidos, pois a questão social influencia muito na ideia que o estudante faz de meio ambiente e de que forma se relaciona com ele, o que é fundamental para uma aprendizagem mais efetiva e consequentemente para a conscientização. Essa importante relação fica evidenciada inclusive na missão do IFPR, presente no PD2:

Promover a educação profissional e tecnológica, pública, de qualidade, socialmente referenciada, por meio do ensino, pesquisa e extensão, visando à formação de cidadãos críticos, autônomos e empreendedores, comprometidos com a sustentabilidade (IFPR f, 2015, p. 26).

Analisando os resultados relatados na Tabela 2 é possível também perceber um nítido aumento nas incidências da palavra "sustentabilidade", aumentando de 2 para 24, quando comparamos PD e PD2, respectivamente. Se no primeiro Plano de Desenvolvimento Institucional percebemos a sustentabilidade apenas na missão e na visão do IFPR, observamos que no Plano de 2014 a 2018 a sustentabilidade está presente em grande parte das atividades que o IFPR se propõe a desenvolver, desde a economia de recursos financeiros até a ideia de conservação ambiental. 
De acordo com Boff (2012) a ideia de sustentabilidade surgiu a partir da grave situação de desequilíbrio que nós estamos vivendo nas últimas décadas, de maneira que muitas organizações, empresas e instituições passaram a agregar esse conceito aos processos $e$ às atividades desenvolvidas. Por este motivo o aumento da incidência do termo sustentabilidade no PD e PD2 pode indicar a atual preocupação e a tentativa da instituição de ensino de se adequar à nova realidade de baixa disponibilidade de recursos. Outra questão importante é o reflexo também na forma de se conduzir as práticas pedagógicas, que devem garantir a formação de alunos conscientes da inter-relação entre o social, econômico e ambiental enunciados pela sustentabilidade. Essa preocupação fica clara quando analisamos a identidade e os compromissos do IFPR, presentes no PD2:

A institucionalidade do IFPR surge com o desafio de construir uma nova identidade escolar, que, enraizada na história, se projete para o futuro como protagonista de transformações, refletindo sobre as necessidades do sujeito a partir da análise das esferas social, econômica e cultural, marcando os olhares com 0 viés da inclusão, da sustentabilidade $e$ da democratização (IFPR f, 2015, p. 29)

A inter-relação mencionada é também o reflexo de uma das demandas propostas pela PNEA, quando enuncia em seu Art. $4^{\circ}$, os princípios básicos para a Educação Ambiental, nos quais o meio ambiente deve ser considerado a partir das relações estabelecidas com o meio e a sua dependência entre os fatores econômicos, sociais e ambientais. Esta relação está também presente no Art. 9 das Diretrizes Curriculares Nacionais para a Educação Ambiental, que demandam a inserção de conteúdos voltados à ética socioambiental dos alunos.

A análise Estatuto do IFPR (ES) evidenciou a grande necessidade da integração entre meio ambiente e sociedade. Das palavras-chave consultadas estavam presentes 2 incidências do termo "meio ambiente". De acordo com o documento uma das finalidades do IFPR é:

Promover a produção, o desenvolvimento e a transferência de tecnologias sociais, notadamente as voltadas à preservação do meio ambiente (IFPR i, 2015 p. 4).

Outro aspecto que o Estatuto traz é a necessidade de se pensar a pesquisa como uma fonte para o desenvolvimento tecnológico, social e ambiental:

As ações de pesquisa, em todos os níveis e modalidades de ensino, contribuem para o progresso da ciência e da tecnologia, o desenvolvimento social, a preservação do meio ambiente e o respeito à vida (IFPR $\mathrm{i}, 2015, \mathrm{p} .14)$. 
De acordo com Layrargues (2004), a concepção científica de meio ambiente contribui de forma expressiva para a construção de um cidadão mais crítico, em bases mais sólidas e concretas propiciadas pelo estudo do meio natural.

Todos os documentos analisados, que contém as palavras-chave utilizadas no estudo, associam a questão ambiental à ideia de preservação, o que é uma fragilidade apresentada, uma vez que de acordo com a Política Nacional de Educação Ambiental a coletividade deve construir competências para que ocorra a utilização racional dos recursos naturais, o que demonstra uma concepção muito mais voltada para a ideia de conservação, como podemos observar no Art. $1^{\circ}$ da PNEA:

Entendem-se por educação ambiental os processos por meio dos quais o indivíduo e a coletividade constroem valores sociais, conhecimentos, habilidades, atitudes e competências voltadas para a conservação do meio ambiente, bem de uso comum do povo, essencial à sadia qualidade de vida e sua sustentabilidade (BRASIL, 1999).

Para Menezes e Siena (2010) a preservação reflete uma corrente de pensamentos ligados à defesa do meio natural em suas condições originais, a ideia da natureza intocada. Diferente do termo conservação que de acordo com Lencastre (2006), considera a natureza como um recurso necessário ao desenvolvimento das atividades humanas, mas que deve ser utilizada de forma a considerar os recursos naturais como bens finitos. Essa concepção surgiu a partir do contexto da explosão demográfica e da urgência em suprir as necessidades de uma população que crescente. Para a realidade dos grandes centros urbanos o conhecimento dos conceitos ligados à preservação é de grande importância, porém a adoção de conteúdos relacionados a conservação influi diretamente na ideia participativa do ser humano e o meio natural, estabelecido na Política Nacional de Educação Ambiental.

A análise do contexto, em que as palavras-chave estão inseridas, indica uma inter-relação entre as questões ambientais, sociais e econômicas nas diretrizes educacionais para o ensino profissional no IFPR. Quando analisamos sob a ótica da Política Nacional de Educação Ambiental percebemos um grande cuidado para que os requisitos estabelecidos sejam efetivados ao longo das práticas de ensino nos documentos que apresentam a incidência dos termos de busca. Um ponto fraco observado na análise foi a presença nos documentos, que continham os termos utilizados no estudo, da expressão preservação que se constitui um contrassenso quando a ideia da inter-relação entre sociedade e natureza, possibilitada pelos ideais conservacionistas, é um dos princípios estabelecidos na Política Nacional de Educação Ambiental (PNEA). 
Diante da literatura analisada neste estudo, é possível perceber que preparar os alunos para o uso sustentável dos recursos naturais engloba uma Educação Ambiental voltada para o entendimento mais participativo de todos nas questões do ambiente em sua totalidade (social, econômico e ambiental) e complexidade.

\section{Análise dos documentos de cursos técnicos subsequentes}

A análise dos documentos de cursos técnicos subsequentes indicou que mesmo não existindo a obrigatoriedade por parte da PNEA de conteúdos específicos sobre a temática da Educação Ambiental, muitos deles apresentam elevada incidência dos termos utilizados no estudo "meio ambiente", "ambiental" e "sustentabilidade", como é o caso do curso Técnico em Edificações. Esse fato indica uma boa articulação entre as diretrizes estabelecidas pela instituição a respeito da temática ambiental com as diretrizes da Política Nacional de Educação Ambiental.

Verificando os documentos dos cursos técnicos subsequentes foi possível perceber que as questões ambientais se apresentam bastante difundidas, pois as palavras-chave foram verificadas em 14 dos 16 cursos analisados.

A Figura 1 apresenta os resultados obtidos com as buscas de palavraschave, na qual é possível observar claramente uma maior predominância no curso técnico em Edificações (37 incidências se somarmos o resultado da busca pelas três palavras-chave).

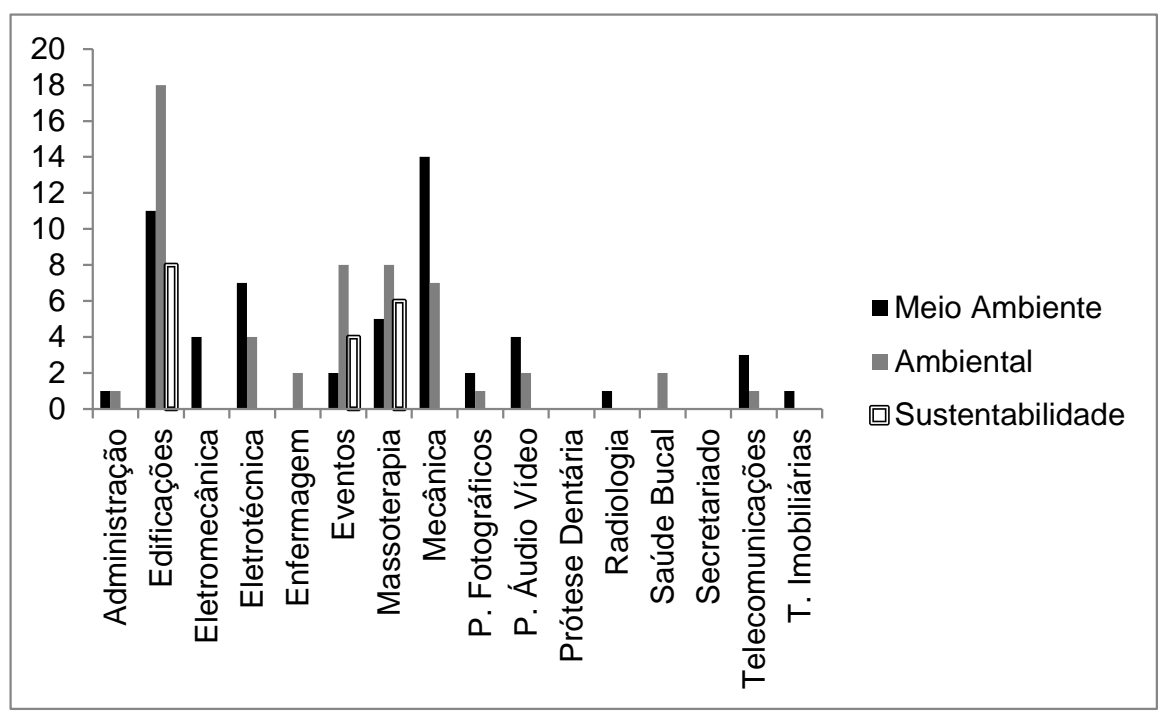

Figura 1: Resultado das buscas por palavras-chave nos documentos de cursos técnicos subsequentes do IFPR.

Fonte: os autores. 
Outro curso que se destacou entre as buscas realizadas foi o Técnico em Mecânica somando 21 incidências para os termos pesquisados, seguido do Técnico em Massoterapia com 19. Os outros cursos técnicos apresentaram incidências que variaram de 1 até 14 .

Os cursos de Prótese Dentária e de Secretariado não evidenciaram em seus documentos as práticas relacionadas às questões ambientais, uma vez que nenhuma das palavras chave utilizadas foram encontradas, o que não indica necessariamente que práticas ligadas à Educação Ambiental não são consideradas no processo de ensino e aprendizagem.

De acordo com a PNEA a Educação Ambiental deve ser aplicada ao longo de todos os níveis e modalidades de educação devendo adotar medidas para que esse processo ocorra em conjunto a todas as disciplinas do currículo formal dos alunos:

Art. 10. A educação ambiental será desenvolvida como uma prática educativa integrada, contínua e permanente em todos os níveis e modalidades do ensino formal.

$\S 1^{\circ}$ A educação ambiental não deve ser implantada como disciplina específica no currículo de ensino (BRASIL, 1999).

Por esse motivo podemos inferir que os cursos de Prótese Dentária e de Secretariado provavelmente abordam as questões ambientais ao longo das disciplinas de forma transversal, uma vez que as diretrizes previstas nos documentos escolares do IFPR estabelecem a necessidade de integrar o social, o econômico e o ambiental nas práticas pedagógicas.

A elevada quantidade de incidências das palavras-chave nos documentos do curso Técnico em Edificações pode estar relacionada, além da formação integral prevista nos documentos escolares, à tendência atual de adequar as construções aos padrões da necessária economia de recursos naturais. De acordo com Silva (2009), as construções que levam em consideração os parâmetros da sustentabilidade podem trazer uma economia de até $20 \%$ nos custos com a manutenção.

No curso de Mecânica se observou 21 incidências dos termos de busca devido a presença de disciplinas que tratam as questões ambientais na visão dos processos que envolvem esta área como, por exemplo, os impactos ambientais resultantes da construção de usinas para geração de energia, sendo inclusive um dos objetivos específicos do curso a articulação entre os conteúdos técnicos com as questões ambientais.

No técnico em Massoterapia as 19 incidências das palavras-chave refletem a relação entre a qualidade ambiental com a saúde humana e de que forma os aspectos ambientais auxiliam na formação integral desses profissionais.

revista brasileira educação ambiental 
A Educação Ambiental, mesmo que não evidente em alguns planos de curso, possivelmente está inserida ao longo da formação dos alunos do IFPR, já que os documentos escolares indicam a integração entre meio ambiente e sociedade como finalidade e objetivo para a formação ao longo do desenvolvimento das atividades de ensino na instituição.

\section{Conclusões}

Diante dos resultados obtidos foi possível constatar que os documentos escolares apresentam o compromisso para a formação de alunos cientes de seu papel na atual realidade de degradação dos recursos naturais. A integração entre os ideais econômicos, sociais e ambientais, previstos pela Política Nacional de Educação Ambiental e sistematizada pelas Diretrizes Curriculares Nacionais para a Educação Ambiental está refletida em alguns dos documentos analisados neste estudo. Mesmo promovendo a articulação os documentos escolares apresentaram uma pequena incidência dos termos de busca, o que pode refletir uma Educação Ambiental que precisa ser fortalecida por meio de normativas específicas que tratam da temática na instituição de ensino.

A análise dos documentos de curso evidenciou uma elevada incidência dos termos pesquisados. Algumas formações possuem inclusive disciplinas voltadas à temática ambiental, como é o caso dos cursos Técnico em Edificações, Técnico em Mecânica e Técnico em Massoterapia, mesmo sendo formações que não estão diretamente relacionadas ao estudo das questões ambientais. Esse resultado reflete o direcionamento da educação profissional para que os estudantes entendam as questões ambientais envolvidas ao longo das atividades humanas.

\section{Agradecimentos}

Ao Instituto Federal do Paraná - IFPR por fornecer as informações necessárias e ao apoio do Centro Universitário Internacional - UNINTER que possibilitou a realização do estudo.

\section{Referências}

BARBIERI, J.C. Gestão ambiental empresarial: conceitos, modelos e instrumentos. 2ª . ed., São Paulo: Saraiva, 2007.

BARBIERI, J.C. Desenvolvimento e meio ambiente: as estratégias de mudanças da agenda 21. 13ª . ed. Petrópolis: Vozes, 2011.

BOFF, L. Sustentabilidade: o que é, o que não é. Petrópolis: Vozes, 2012.

BRASIL. Lei no. 6.938, de 31 de agosto de 1981. Dispõe sobre a Política Nacional do Meio Ambiente, seus fins e mecanismos de formulação e aplicação, e dá outras providências. Brasília, DF, 1981. Disponível em: <http://www.planalto.gov.br/ccivil 03/leis/L6938.htm>. Acesso em: 7 jul. 2017. 
BRASIL. Constituição da República Federativa do Brasil. Brasília, DF, 1988. Disponível

$<$ http://www.planalto.gov.br/ccivil 03/constituicao/constituicao.htm>. Acesso em: 7 jul. 2017.

BRASIL. Lei no. 9.394, de 20 de dezembro de 1996. Lei de Diretrizes e Bases da Educação Nacional. Brasília, DF, 1996. Disponível em: $<$ http://www.planalto.gov.br/ccivil 03/leis/L9394.htm>. Acesso em: 7 jul. 2017.

BRASIL. Lei $\mathbf{n}^{\circ}$. 9.795, de 27 de abril de 1999. Política Nacional de Educação Ambiental. Brasília, DF, 1999. Disponível em: <http://www.planalto.gov.br/ccivil 03/leis/L9795.htm>. Acesso em: 7 jul. 2017.

BRASIL. Lei no. 11.892, de 29 de dezembro de 2008. Institui a Rede Federal de Educação Profissional, Científica e Tecnológica. Brasília, DF, 2008. Disponível em: <http://www.planalto.gov.br/ccivil 03/ ato20072010/2008/lei//11892.htm>. Acesso em: 7 jul. 2017.

BRASIL - Ministério da Educação. Resolução n. 2, de 15 de junho de 2012. Estabelece as Diretrizes Curriculares Nacionais para a Educação Ambiental. Brasília, DF, 2012. Disponível em: < http://portal.mec.gov.br/index.php?option=com docman\&view=download\&alias $=10988$-rcp002-12-pdf\&category slug=maio-2012-pdf\&ltemid=30192>. Acesso em: 7 jul. 2017.

COSTA, H. S. M.. Meio ambiente e desenvolvimento: um convite à leitura. In: HISSA, C. E. V.. Saberes ambientais: desafios para o conhecimento disciplinar. Belo Horizonte: UFMG, 2008. p. 79-108.

IFPR a - INSTITUTO FEDERAL DO PARANÁ. O Instituto. Disponível em: $<$ http://reitoria.ifpr.edu.br/menu-institucional/institucional $>$. Acesso em: 29 mai. 2015.

IFPR b - INSTITUTO FEDERAL DO PARANÁ. Concepção de avaliação da aprendizagem. Disponível em: <http://curitiba.ifpr.edu.br/wpcontent/uploads/2011/06/AVALIACAO retificada 2012.pdf>. Acesso em: 14 ago. 2015.

IFPR c - INSTITUTO FEDERAL DO PARANÁ. Regimento Geral. Disponível em: $\quad<$ http://curitiba.ifpr.edu.br/wp-content/uploads/2011/06/regimento-geralIFPR.pdf>. Acesso em: 14 ago. 2015.

IFPR d - INSTITUTO FEDERAL DO PARANÁ. Regimento Interno Comum aos Câmpus do Instituto Federal. Disponível em: http://curitiba.ifpr.edu.br/wpcontent/uploads/2011/06/Resolu\%C3\%A7\%C3\%A30-08.14-Regimento-internocomum-aos-campus-09.05.14.pdf>. Acesso em: 14 ago. 2015.

IFPR e - INSTITUTO FEDERAL DO PARANÁ. Plano de Desenvolvimento Institucional 2009 a 2013. Disponível em: <http://info.ifpr.edu.br/wpcontent/uploads/PDI.pdf>. Acesso em: 14 ago. 2015. 
IFPR $\mathrm{f}$ - INSTITUTO FEDERAL DO PARANÁ. Plano de Desenvolvimento Institucional 2014 a 2018. Disponível em: <http://info.ifpr.edu.br/wpcontent/uploads/pdi-2014-2018-versao-final-1.pdf>. Acesso em: 14 ago. 2015.

IFPR g - INSTITUTO FEDERAL DO PARANÁ. Manual dos professores Campus Curitiba. Disponível em: <http://curitiba.ifpr.edu.br/wpcontent/uploads/2011/06/Manual do Professor 1.pdf >. Acesso em: 14 ago. 2015.

IFPR h - INSTITUTO FEDERAL DO PARANÁ. Resolução no. 44 de 09 de Dezembro de 2013. Disponível em: <http://reitoria.ifpr.edu.br/wpcontent/uploads/2013/02/Res.-44.20131.pdf>. Acesso em: 14 ago. 2015.

IFPR i - INSTITUTO FEDERAL DO PARANÁ. Estatuto do Instituto Federal do Paraná. Disponível em: http://reitoria.ifpr.edu.br/wpcontent/uploads/2011/09/estatuto.pdf acesso em 14 de agosto de 2015.

JACOBI, P.. Educação ambiental, cidadania e sustentabilidade. Cadernos de Pesquisa, n. 118, p. 189-205, 2003. Disponível em: < http://atividadeparaeducacaoespecial.com/wpcontent/uploads/2014/09/cidadaniaesustobriga.pdf>. Acesso em: 7 jul. 2017.

KLUCZKOVSKI, A.M.R.G. Introdução ao estudo da poluição dos ecossistemas. Curitiba: InterSaberes, 2015. 275 p.

LAYRARGUES, P.P. (coord.). Identidades da educação ambiental brasileira. Brasília: Ministério do Meio Ambiente, Diretoria de Educação Ambiental, 2004.

LENCASTRE, M.P.A. Ética ambiental e educação nos novos contextos da ecologia humana. Revista Lusófona de Educação, v. 8, p. 29-52, 2006. Disponível em:

http://www.scielo.mec.pt/scielo.php?script=sci arttext\&pid=S1645-

72502006000200003>. Acesso em: 7 jul. 2017.

LOUREIRO, C.F.B. Trajetória e fundamentos da educação ambiental. 4 a ed. São Paulo: Cortez, 2012.165 p.

MAZZAROTTO, A.S.; BERTE, R. Gestão ambiental no mercado empresarial. Curitiba: InterSaberes, 2013.

MENEZES, D.S.; SIENA, O. Ambientalismo no Instituto Chico Mendes de Conservação da Biodiversidade (ICMBIO) na Amazônia legal. Organizações \& Sociedade, v. 17, n.54, p. 479-498, 2010. Disponível em: < http://www.scielo.br/scielo.php?script=sci arttext\&pid=S1984-

92302010000300008>. Acesso em: 7 jul. 2017.

MILLER JR., G.T. Ciência Ambiental. São Paulo: Cengage Learning, 2011.

REIS, S.L.A.; BELLINI, M. Representações sociais: teoria, procedimentos metodológicos e educação ambiental. Human and Social Sciences, v. 33, n. 2, p. 149-159, 2011. Disponível em: $<$ http://periodicos.uem.br/ojs/index.php/ActaSciHumanSocSci/article/view/1025 6r>. Acesso em: 7 jul. 2017. 
SILVA, M.G. Questão ambiental e desenvolvimento sustentável: um desafio ético-político ao serviço social. São Paulo: Cortez, 2010. 254 p.

SILVA, S.M.G.M. A Sustentabilidade e o Conforto das Construções. 2009. 412 f. Tese (Doutorado em Engenharia Civil). Escola de Engenharia, Universidade do Minho. Disponível em: $<$ http://repositorium.sdum.uminho.pt/handle/1822/10245>. Acesso em 7 jul. 2017.

STADLER, A.; MAIOLI, M.R. Organizações e desenvolvimento sustentável. Curitiba: Ibpex, 2011. 